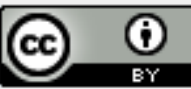

\title{
A INDÚSTRIA TÊXTIL NA REGIÃO NORDESTE: GARGALOS, POTENCIALIDADES E DESAFIOS
}

\section{TEXTILE INDUSTRY IN THE NORTHEAST REGION: RESTRAINTS, POTENTIALITIES AND CHALLENGES}

\author{
Fernando Luiz Emerenciano Viana \\ Mestre em Engenharia de Produção \\ Professor da Faculdade de Ensino e Cultura do Ceará \\ Consultor Interno do Banco do Nordeste do Brasil - BNB \\ Escritório Técnico de Estudos Econômicos do Nordeste - ETENE \\ Av. Paranjana. 5700 - Bloco A 2 inferior Bairro Passaré \\ Telefone: (85) 3299-3034 E-mail: fernandoviana@bnb.gov.br

\section{Roberto Ednísio Vasconcelos Rocha \\ Mestre em Engenharia de Produção \\ Professor da Faculdade Farias Brito} \\ Gerente de Negócios do Banco do Nordeste do Brasil - BNB \\ Ambiente de Negócios Empresariais e de Atração de Investimentos \\ Av. Paranjana. 5700 - Bloco E 1 superior Bairro: Passaré \\ Telefone: (85) 3299-5194 E-mail: robertoevr@bnb.gov.br
}

\section{Fernando Ribeiro de Melo Nunes}

Doutor em Engenharia de Produção

Professor do Mestrado em Logística e Pesquisa Operacional da Universidade Federal do Ceará

Assessor da Secretaria de Ciência, Tecnologia e Educação Superior do Estado do Ceará

End.: Campus do Pici - Centro de Tecnologia, Departamento de Mecânica e Produção

Bairro: Pici

Telefone: (85) 3366-9632 E-mail: ferimene@ secrel.com.br 


\title{
RESUMO
}

Este trabalho apresenta uma avaliação da competitividade da Indústria Têxtil na Região Nordeste, bem como uma relação de gargalos, potencialidades e desafios. As observações foram feitas a partir de pesquisa bibliográfica e documental. Foram realizadas análises da indústria têxtil no âmbito brasileiro e mais detalhadamente no campo de atuação nordestino. Os estados do Ceará, Bahia, Paraíba e Rio Grande do Norte destacaram-se na produção e no número de empregos no setor. Questões logísticas ligadas à integração e adensamento da cadeia produtiva a partir da articulação com a indústria de confecções, infra-estrutura e modernização tecnológica são apontadas como temas recorrentes ao alavancamento da Indústria na Região.

Palavras-chave: Indústria Têxtil, Competitividade, Região Nordeste.

\begin{abstract}
This study presents a competitiveness evaluation of the Textile Industry in the Northeast Region, as well as a relation of restraints, potentialities and challenges. The observations have been made from a bibliographic and documental research. There have been done analysis of the Industry under the Brazilian scope and in more detail regarding the northeastern action field. . The states of Ceará, Bahia, Paraíba and Rio Grande do Norte have came forward in the production and number of jobs in the sector. Logistics matters related to integration and consolidation of the productive chain from the articulation with the confections industry, infrastructure and technological modernization are pointed out as recurring themes to the industrial acceleration in the Region.
\end{abstract}

Key-words: Textile Industry, Competitiveness, Northeast Region.

\section{INTRODUÇÃO}

A Indústria Têxtil possui amplo rebatimento em diversas cadeias produtivas como a cotonicultura, máquinas, petroquímica e de confecções. A atividade contempla quatro segmentos de atuação que são a fiação, tecelagem, malharia e acabamento. O Estado de São Paulo é o maior estado produtor de têxteis do país em todos os segmentos da cadeia, da fiação às confecções.

Segundo Faria (2005), o Brasil se destaca como o quinto maior produtor têxtil do mundo, devido, dentre outros fatores, à sua auto-suficiência na produção de algodão. Em relação ao setor de vestuário/confecções, chega a produzir 7,2 bilhões de peças de vestuário / ano, sendo o $2^{\circ}$ maior produtor mundial de índigo; o $3^{\circ}$ maior produtor de malha; o $5^{\circ}$ maior 


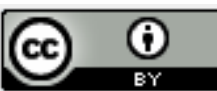

produtor de confecção; o $7^{\circ}$ maior produtor mundial de fios e filamentos e o $8^{\circ}$ produtor mundial de tecidos.

Na Região Nordeste, o principal estado produtor é o Ceará, sendo o setor no estado basicamente formado por médias e grandes empresas, ocupando o segundo lugar no País. A indústria têxtil responde por 16,5\% do PIB estadual. São 15 empresas que geram 18 mil empregos. Além destas segue-se também uma ramificação mais artesanal focada no segmento de produção de redes nos municípios de Jaguaruana e Irauçuba, esta também com bordados.

A produção é praticamente toda voltada para alimentar o mercado interno de confecções, tendo assim participação pífia na pauta de exportação regional, entretanto deve ser salientado o seu déficit comercial, por exemplo, no estado do Ceará em que a importação de produtos têxteis, exceto vestuário, em 2006 foi de U\$ 35 milhões enquanto a exportação foi de US\$ 16 milhões, resultado este potencializado pela invasão, às vezes ilegal, dos produtos chineses.

O setor têxtil como um todo está passando por um processo de reestruturação devido ao fim do acordo que regulamentava as cotas de importação e exportação, em janeiro de 2005.

O objetivo deste trabalho é traçar uma caracterização sobre a Indústria Têxtil na Região Nordeste a partir de alguns aspectos produtivos e mercadológicos, bem como o levantamento de gargalos, potencialidades e desafios a serem superados.

\section{COMPETITIVIDADE INDUSTRIAL}

O interesse pelo tema competitividade no Brasil intensificou-se a partir do final da década de oitenta, após o início dos efeitos das transformações então em curso na economia mundial, acentuando-se com a abertura da economia ocorrida no início da década de noventa.

Diversos fenômenos e variáveis podem ser considerados como explicativos da competitividade. Por conta disso, o termo permite uma diversidade de definições. Na análise de Porter (1993), a formulação mais moderna da Teoria da Vantagem Comparativa, devida a Heckscher e Ohlin, baseia-se na idéia de que todas as nações possuem tecnologia equivalente, mas diferem na dotação dos fatores produtivos, que nada mais são dos que os insumos básicos necessários à produção. Dessa forma, os países ganham vantagem comparativa de fatores em indústrias que fazem uso intensivo dos fatores que possuem em abundância, exportando esses produtos e importando aqueles para os quais têm uma desvantagem comparativa de fatores. 
O conceito de competitividade evoluiu, tendo a tecnologia assumido um papel primordial na definição de padrões de competitividade a nível mundial. Assim sendo, Porter (1993) apresenta a teoria da Vantagem Competitiva, cujo elemento central é a inovação em métodos e tecnologia, partindo da premissa que a competição é evolutiva, devendo-se incluir em seu conceito mercados segmentados, produtos diferenciados, diversidades tecnológicas e economias de escala.

Consoante Coutinho e Ferraz (1993), o debate sobre o conceito de competitividade e seus fatores evoluiu de uma visão estática para uma visão dinâmica, ao incluir o papel das estratégias competitivas e o caráter temporal das vantagens competitivas. Na visão dinâmica, tanto desempenho quanto eficiência resultam de capacitações acumuladas e estratégias competitivas adotadas pelas empresas, em função de suas percepções quanto ao processo concorrencial e ao ambiente onde estão inseridas. Considerando essa nova visão, os autores definem a competitividade como a capacidade de uma empresa de formular e implementar estratégias concorrenciais que lhe permitam conservar, de forma duradoura, uma posição sustentável no mercado.

Prosseguindo em suas análises, Coutinho e Ferraz (1993) dividem os determinantes da competitividade em internos às empresas, estruturais (referindo-se a setores e complexos industriais) e de natureza sistêmica.

Os fatores internos às empresas são aqueles que estão sob sua esfera de decisão, incluindo os estoques de recursos acumulados pela empresa, as vantagens competitivas que possuem e a sua capacidade de ampliá-las, baseados em quatro áreas de competência:

- Gestão: marketing, serviços pós-venda, finanças, administração, planejamento etc.;

- Inovação: produto, processo, transferência de tecnologia etc.;

- Produção: atualização de equipamentos, técnicas organizacionais, qualidade etc.;

- Recursos Humanos: produtividade, qualificação, flexibilidade etc.

Os fatores estruturais são aqueles que estão parcialmente sob a área de influência da empresa e que caracterizam o ambiente competitivo no qual ela concorre. São os relacionados a:

- Características dos Mercados: tamanho e dinamismo, grau de sofisticação, acesso a mercados internacionais etc.;

- Configuração da Indústria: desempenho e capacitação, estrutura patrimonial e produtiva, articulação na cadeia produtiva etc.; 
- Concorrência: regras que definem condutas e estruturas empresariais em suas relações com consumidores e concorrentes etc.

Os fatores sistêmicos da competitividade são aqueles determinados por fatores exógenos à empresa e à estrutura industrial correspondente. Afetam as características do ambiente competitivo e variam de importância, dependendo das vantagens competitivas que as empresas de um país têm ou deixam de ter frente aos concorrentes no mercado internacional. Podem ser:

- Macroeconômicos: taxa de câmbio, carga tributária, taxa de crescimento do produto interno, oferta de crédito e taxas de juros, política salarial etc.;

- Político-institucional: políticas tributária e tarifária, apoio fiscal ao risco tecnológico, poder de compra do governo etc.;

- Regulatórios: políticas de proteção à propriedade industrial, de preservação ambiental, de defesa da concorrência e proteção ao consumidor, de regulação do capital estrangeiro etc.;

- Infra-estruturais: disponibilidade, qualidade e custo de energia, transportes, telecomunicações, insumos básicos e serviços tecnológicos etc.;

- Sociais: sistema de qualificação da mão-de-obra (educação profissionalizante e treinamento), políticas de educação e formação de recursos humanos, legislação trabalhista e de seguridade social etc.;

- Internacionais: tendências do comércio mundial, fluxos internacionais de capital, de investimento de risco e de tecnologia, acordos internacionais etc.

Freire (2000) analisou alguns indicadores qualitativos, tais como relacionamento com clientes e fornecedores, recursos humanos, qualidade, estratégias, técnicas, métodos e programas de gestão da produção, visando medir a competitividade industrial através da inserção das empresas no comércio internacional.

Tendo-se como referência os indicadores qualitativos analisados, Freire (2000) ressalta que as empresas nordestinas que vendem seus produtos para os mercados nacional e externo possuem práticas gerenciais diferentes daquelas que alcançam somente os mercados local e regional. Assim sendo, as empresas com maior área de atuação apresentam as seguintes características de diferenciação:

- Utilizam em maior escala procedimentos para registrar reclamações recebidas, pesquisar informações sobre as necessidades dos clientes e estabelecer parcerias em programas de 
qualidade;

- Possuem relacionamento mais intenso com os fornecedores;

- Apresentam maior grau de utilização de modernas técnicas, métodos e programas de gestão da produção;

- Seus recursos humanos possuem nível de escolaridade mais elevado em relação às empresas de atuação local e regional.

A figura 1 apresenta os fatores explicativos da competitividade evidenciados pelo referido trabalho.

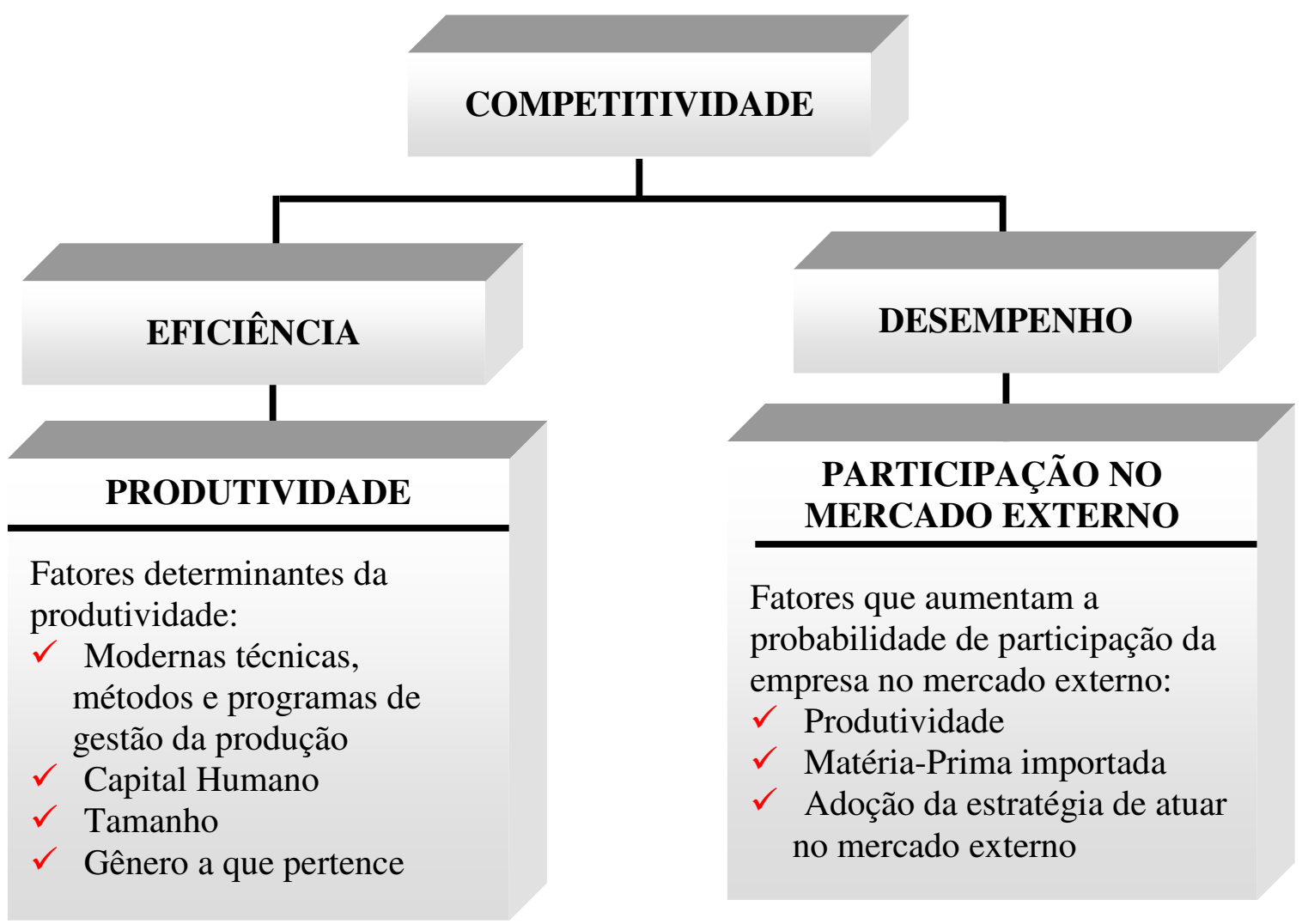

\section{Figura 1: Fatores Explicativos da Competitividade da Indústria Nordestina}

Fonte: Freire (2000)

\section{METODOLOGIA}

Considerando as definições de Vergara (2004), a presente pesquisa pode ser classificada, quanto aos fins, como exploratória, já que há pouco conhecimento acumulado e sistematizado sobre a Indústria Têxtil na Região Nordeste. 
Quanto aos meios, o trabalho pode ser definido como pesquisa bibliográfica e documental, onde foram abordadas as principais características da Indústria Têxtil a partir de pesquisa em livros e artigos científicos além de documentos de sindicatos e instituições, bem como se abordou o estado da arte relacionado com a competitividade industrial.

Considerando a experiência prévia dos autores na realização de trabalhos sobre o setor em estudo, procurou-se utilizar publicações anteriores dos próprios autores, bem como dados adicionais, inclusive secundários, no sentido de discorrer sobre e discutir as temáticas que contribuem para a consecução dos objetivos do presente trabalho.

\section{ASPECTOS DA PRODUÇÃO DO SETOR TÊXTIL}

O algodão se encontra com a indústria têxtil em sua fase final, em que são encontradas as fiações para o algodão em pluma. As fiações são os elos iniciais da cadeia têxtil, que utiliza como insumos básicos tanto as fibras naturais, provenientes do algodão, quanto as fibras sintéticas, derivadas da indústria química.

Existem, também, as fibras manufaturadas, que são obtidas a partir da cadeia petroquímica ou da celulose, conhecidas como fibras químicas. Estas são mais resistentes a atritos e tensionamentos e proporcionam um elevado aumento na produtividade dos teares.

O processo produtivo de inserção das fibras é descrito pelo caderno análise setorial da Gazeta Mercantil (1999, p. 17).

\footnotetext{
"As fibras em flocos, ao entrarem na primeira etapa do processo têxtil, a fiação, são transformadas em têxteis lineares denominados fios, pela descompactação, limpeza e paralelização das fibras, seguidas de torção. No processo open end, após a paralelização obtém-se a coesão das fibras pelo entrelaçamento de algumas em torno do conjunto das demais. As fibras em filamentos contínuos, por já se constituírem de têxteis lineares, podem ser fornecidas diretamente às tecelagens ou malharias, que transformam têxteis lineares em têxteis de superfície: os tecidos planos ou malha".
}

Segundo a mesma fonte, após a formação do tecido propriamente dito, esses têxteis seguem para a etapa de beneficiamento, onde são retiradas todas as impurezas (ceras, graxas, naturais, gomas, resíduos de lubrificantes, coloração natural) preexistentes ou adquiridas durante a fiação, ou vão para o tecimento, para ser realizado o tingimento ou a estampagem do tecido. 


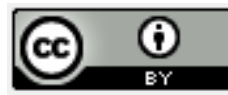

De acordo com a Gazeta Mercantil (1999), o segmento de fiação caracteriza-se pela grande integração vertical com as outras etapas do processo produtivo, principalmente, as tecelagens, de modo que cerca de $78 \%$ das fiações no Brasil são integradas com a tecelagem.

No segmento de tecelagem, não se encontra um grande nível de verticalização da produção. As integrações ocorrem somente nas grandes empresas do setor, normalmente produtoras de roupa branca (cama, mesa e banho) e tecidos de algodão, como denim e brins. Os tecidos planos são obtidos a partir do entrelaçamento dos fios do urdume no sentido do comprimento e da trama no sentido da largura. São utilizados nesse processo os equipamentos conhecidos como teares, que possuem grande variedade e modelos, podendo ser manuais, mecânicos ou automáticos.

No segmento de malharia, o grau de verticalização é considerável, principalmente com a confecção. Cerca de $58 \%$ dessas empresas são integradas, entretanto poucas possuem o domínio do processo completo, da fiação à confecção. Apenas as grandes malharias, como a Coteminas, possuem tal integração. Os tecidos de malha são obtidos, assim como nos tecidos planos, a partir do entrelaçamento de conjunto de fios de malha na largura, conhecido como malharia por trama, que é utilizado usualmente na produção de meia malha (tecido das camisetas), e no comprimento, conhecido como malharia por urdume, que é utilizado usualmente na produção de tecidos trabalhados e rendados.

As operações realizadas no setor de beneficiamento ocorrem de acordo com a utilização do produto, por isso não seguem padrão seqüencial, buscando adequar o tecido a alguma determinada aplicação, através de impermeabilizações, encorpamentos, amaciamentos, calandragens, incorporação de características antimancha e anti-ruga, entre outras. Salientem-se, também, os tratamentos especiais dados aos fios tintos quando estes se destinam à linha de costura ou a insumos para produzir tecidos listrados ou xadrezes.

Devido às descontinuidades das operações e flexibilidades no processo produtivo, o acesso à tecnologia é incorporado à aquisição de máquinas e equipamentos, que são bastante acessíveis no mercado, não se constituindo em barreira à entrada no setor. O setor é na verdade incorporador de tecnologia de outros setores, principalmente de fibras sintéticas e corantes desenvolvidas em laboratório. Sua estratégia de concorrência baseia-se na melhoria de produtividade a partir da modernização do parque industrial e desenvolvimento de novos produtos, mas esses fatores, no Brasil, encontram-se ainda defasados em relação ao padrão mundial (VIANA, 2005b). 


\section{INDÚSTRIA TÊXTIL NORDESTINA}

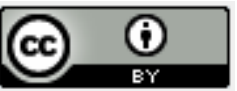

Para se ter uma visão geral da indústria têxtil do Nordeste, torna-se relevante visualizar a distribuição da produção nos diversos estados da Região, bem como a configuração do número de vínculos empregatícios no setor.

Utilizando a variável conhecida como Valor de Transformação Industrial - VTI, que se assemelha ao Produto Interno Bruto Industrial, definida como sendo a diferença entre o Valor Bruto da Produção Industrial - VBPI e o Custo das Operações Industriais - COI, reconhecido como a monetarização do valor adicionado pelo processo produtivo das empresas, constata-se, em relação aos produtos têxteis, a evolução da maioria dos estados nordestinos, conforme mostrado na série histórica (2001-2006) da tabela 1, em que os valores estão expressos em R \$ 1 mil.

Tabela 1 - VTI dos estados nordestinos referente à produção de artigos têxteis (exceto vestuário)

\begin{tabular}{lcccccc}
\hline \multicolumn{1}{c}{ Estados } & $\mathbf{2 0 0 1}$ & $\mathbf{2 0 0 2}$ & $\mathbf{2 0 0 3}$ & $\mathbf{2 0 0 4}$ & $\mathbf{2 0 0 5}$ & $\mathbf{2 0 0 6}$ \\
\hline Ceará & 400.271 & 634.165 & 532.635 & 598.377 & 467.425 & 471.818 \\
Bahia & 254.655 & 296.453 & 252.965 & 345.706 & 260.150 & 282.513 \\
Paraíba & 322.082 & 277.813 & 289.819 & 310.564 & 320.529 & 201.727 \\
Rio Grande do & 109.767 & 114.603 & 217.712 & 241.985 & 305.682 & 225.591 \\
Norte & 88.282 & 115.121 & 141.122 & 174.406 & 143.705 & 171.058 \\
Sergipe & 106.439 & 118.623 & 107.002 & 113.432 & 114.286 & 195.610 \\
Pernambuco & 27.232 & 25.005 & 27.469 & 28.138 & 27.969 & 32.666 \\
Alagoas & 6.499 & 6.941 & 6.718 & 6.674 & 7.211 & 6.466 \\
Maranhão & 2.292 & 1.408 & 1.475 & 4.149 & 4.789 & 5.560 \\
Piauí & & & & & & \\
\hline
\end{tabular}

Fonte: Instituto Brasileiro de Geografia e Estatística - IBGE (2008)

A tabela 2 apresenta os dados da Relação Anual de Informações Sociais - RAIS, referentes ao número de vínculos empregatícios dos estados nordestinos em 2005. 
Tabela 2 - Números de vínculos empregatícios na fabricação de produtos têxteis em 2005 (grupo 17 da $\mathrm{CNAE}^{1}$ )

\begin{tabular}{lc}
\hline \multicolumn{1}{c}{ UF } & Vínculos empregatícios \\
\hline Ceará & 16.419 \\
Rio Grande do Norte & 9.961 \\
Paraíba & 8.926 \\
Bahia & 8.071 \\
Pernambuco & 5.219 \\
Sergipe & 4.410 \\
Maranhão & 338 \\
Piauí & 149 \\
Alagoas & 1.125 \\
Região Nordeste & $\mathbf{5 4 . 7 1 8}$ \\
\hline
\end{tabular}

Fonte: Brasil (2005)

No caso do Nordeste, os estados do Ceará, Paraíba, Bahia e Rio Grande do Norte destacam-se como os que possuem os maiores números de valor transformação industrial e de vínculos empregatícios do setor.

Observando-se os números da tabela, destaca-se, na Região Nordeste, o estado do Ceará, que detém cerca de 30,0\% dos empregos do setor na Região. O Estado de Pernambuco, que historicamente foi um dos grandes produtores do Nordeste, tem perdido participação relativa ao longo dos anos, principalmente devido às estratégias de atração de investimentos, via incentivos fiscais, implementadas recentemente pelos estados do Ceará, Paraíba, Bahia e Rio Grande do Norte.

A indústria têxtil do Ceará está concentrada espacialmente na Região Metropolitana de Fortaleza (RMF), possuindo grandes empresas com alto grau de verticalização, com foco na produção de fios de algodão e tecido denim, com destaque para a Vicunha, maior indústria têxtil da América Latina, que concentra quatro de suas unidades produtivas brasileiras na RMF. Na região nordeste, a Vicunha possui unidades de produção também no Rio Grande do Norte e na Bahia.

No Rio Grande do Norte, a indústria têxtil se concentra na Região Metropolitana de Natal, destacando-se as unidades fabris do grupo Coteminas, segunda maior produtora de têxteis brasileira, que possui três unidades fabris no estado, sendo duas em São Gonçalo do Amarante e uma em Macaíba. Da mesma forma, a Coteminas possui um papel de grande relevância na indústria têxtil da Paraíba, já que possui também naquele estado três plantas fabris, distribuídas em João Pessoa, capital do estado, e Campina Grande.

\footnotetext{
${ }^{1}$ Classificação Nacional de Atividades Econômicas
} 
Com relação à indústria têxtil da Bahia, apesar de não apresentar grandes empresas verticalizadas, as quais concentram-se na Região Metropolitana de Salvador e em Feira de Santana, entende-se que apresenta um grande potencial de crescimento, especialmente devido à presença, no estado, de um pólo de produção de algodão, concentrado espacialmente no Oeste do estado (Barreiras, Luiz Eduardo Magalhães), bem como do pólo petroquímico de Camaçari. Apesar da existência do pólo petroquímico, ainda não existe na Bahia uma produção significativa de fibras têxteis químicas, o que poderia ser estimulado pela presença de uma indústria têxtil forte. De qualquer maneira, a possibilidade de atração para a Bahia de grandes players do setor têxtil apresenta argumentos relevantes.

A participação da indústria nordestina no comércio exterior tem se caracterizado em torno de $27,5 \%$ em valor (US\$ FOB) e 42,8\% em peso líquido nas exportações, além de 16,7\% em valor (US\$ FOB) e 23,8\% em peso líquido nas importações, a partir de 1999, com o início do regime de câmbio flutuante (ROCHA, 2007).

Segundo Diniz e Basques (2004), ocorre um dilema quanto ao desenvolvimento da indústria têxtil na Região, pois o investimento propiciado pelos incentivos fiscais prioriza o emprego, a diversificação e a orientação do mercado local, o que prejudica, muitas vezes, o incremento da qualidade dos processos e produtos. Como os grandes atrativos são os baixos salários da mão-de-obra pouco qualificada e os incentivos fiscais, o incremento da qualidade pode representar aumento de salários e de despesas que afetariam seus diferenciais competitivos locacionais.

\section{GARGALOS DO SETOR}

A partir de $1^{\circ}$ de janeiro de 2005, o comércio mundial de produtos têxteis deixou de ser regulado pelo Acordo Têxtil e Vestuário - ATV e passou a se submeter às regras gerais da Organização Mundial do Comércio - OMC, acabando com as restrições de cotas para importação e exportação, gerando expectativas e preocupações para os países que se beneficiavam do Acordo, como o Brasil.

Para a Confederação Nacional da Indústria - CNI (2005), os mercados que eram mais atingidos pela regulamentação anterior, no caso China e Índia, serão os grandes beneficiários deste desmantelamento de restrições quantitativas, presumindo que os ganhos de fatias de mercado em confecção serão bem maiores que dos que se prevêem para têxteis. 
Como o Brasil tem uma relevância secundária no mercado têxtil internacional, no cenário pós-ATV, o País deve buscar acordos preferenciais de acesso a mercados ou mesmo a adoção de salvaguardas em relação à China e Índia, de onde estão ocorrendo um eventual crescimento de importações, inclusive da subcadeia de sintéticos e artificiais.

Ressalte-se ainda a falta de articulação entre os elos do setor têxtil com o de confecções, que pode ser explicada a partir da origem patrimonial do capital, já que, no caso do Ceará, por exemplo, as grandes empresas localizadas em seu território têm vínculos societários com as regiões Sul e Sudeste, mantendo articulação e ligações comerciais, tecnológicos e culturais com empresas fornecedoras e sediadas nestas regiões (BNB, 2006).

Nunes et al. (2006), em extensa pesquisa com 500 empresas de confecções no Estado do Ceará, destacam alguns gargalos vivenciados por essas empresas, notadamente em relação ao ciclo de suprimento do principal insumo e à grande necessidade de financiamento de capital de giro. Sobre o prazo de entrega de tecido, predominantemente o índigo blue, Nunes et al. (2006) retratam que este demora cerca de 5 dias para 59,97\% das empresas que compram no Ceará e até 30 dias para 57,67\% das empresas que compram das Regiões Sul e Sudeste. O tempo de transporte varia entre 7 e 15 dias para estes tecidos comprados fora do Nordeste.

O prazo médio de pagamento é de 49,36 dias em média, tirados 15 dias de tráfego do fornecedor até a fábrica, 30 dias de estoque da matéria-prima na fábrica, 13 dias do ciclo de fabricação, 19 dias do estoque de produtos acabados para a fábrica, 7 dias para o processo e aprovação de pedidos e separação de mercadorias, 7 dias de tráfego até o cliente e 45 dias de prazo para pagamento pelos clientes, indicando que o confeccionista precisa financiar durante 87 dias sua operação. Não estão aí contabilizados serviços terceirizados de lavanderia, que utilizam 4 dias para roupa jeans, ou de bordados, que utilizam 5 dias para peças femininas.

Tal demora nos prazos leva as empresas de confecções a necessitarem de capital de giro, que chega a 4,49 vezes o seu faturamento mensal, atuando com uma média de 29,58 dias de estoque de matéria-prima, 18,74 dias de estoque de produto acabado e com um ciclo de produção de 12,52 dias para adquirir a rentabilidade média sobre o faturamento de 28,46\%.

Observa-se, então, que a logística de transporte constitui um gargalo relevante que possui impacto na competitividade da indústria têxtil do Nordeste. A indústria têxtil brasileira e, conseqüentemente, a nordestina, é predominantemente fabricante de produtos derivados de fibras naturais, sendo que o principal obstáculo do fornecimento do algodão situa-se na logística de transporte a partir utilização do modal rodoviário como instrumento de 


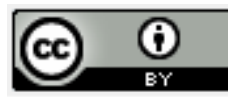

escoamento da produção, estando sujeito a roubos de cargas e ao enfrentamento das dificuldades das estradas brasileiras (VIANA, 2005a).

Vidal e Carneiro (2006) atestam que a partir da safra 2004/05 houve uma queda significativa nos preços da fibra do algodão, causada pela estagnação da demanda e dos elevados estoques mundiais, além da valorização da moeda nacional, que diminui a remuneração do exportador, visto que, por ser commodity, os preços estão atrelados às cotações do mercado internacional.

Campos e Paula (2006) afirmam que a cultura do algodão foi prejudicada devido à inexistência de uma política agrícola específica, além das vantagens de culturas rivais, como soja e milho, que não sofreram tanto com condições macroeconômicas desfavoráveis.

Segundo o BNB (2006 p.329) "a cadeia têxtil possui três fragilidades fundamentais que são a gestão e a qualificação de mão-de-obra, a obtenção de matéria-prima e a necessidade de constante renovação da tecnologia utilizada".

Além disso, Viana (2005b) salienta a alta dependência de incentivos fiscais para permanências de empresas no Nordeste, a tendência de maior consumo de produtos derivados de fibras sintéticas, insumos atualmente importados pelo Nordeste, a baixa competitividade nos segmentos derivados de fibras sintéticas e o alto custo de transporte para aquisição de insumos e distribuição do produto final.

\section{POTENCIALIDADES DO SETOR}

Com a implantação da Ferrovia Transnordestina, tem-se a possibilidade da criação de alternativa logística para o algodão do Centro-Oeste, fator importante para o aumento da competitividade da indústria têxtil nordestina.

A vinda da refinaria de petróleo da Petrobrás/PDVSA para o Estado de Pernambuco possibilitará a criação do Pólo de Poliéster do Nordeste, que será formado por três empreendimentos industriais a serem implantados pela Petrobrás e pelo grupo italiano Mossi \& Ghisolfi (M\&G), associado a uma fábrica de tecidos sintéticos finos do grupo coreano Kabul Synthetics Fiber, que investirá US\$ 45 milhões.

Também em Pernambuco, está sendo implantada uma unidade fabril verticalizada para produção de fibras sintéticas, denominado Projeto CITEPE (Companhia Integrada Têxtil de Pernambuco). Este se configura como projeto integrado entre o setor têxtil e o setor 


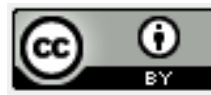

petroquímico, que será produzido pela Petroquisa (braço petroquímico da Petrobras) e a Companhia Integrada do Nordeste - CITENE (associação das empresas Vicunha Têxtil, FIT e Polyenka) em que será utilizado poliéster fabricado segundo os padrões asiáticos de competitividade e com previsão de funcionamento para 2010.

Os produtos nordestinos que mostram melhores condições para serem trabalhados no mercado internacional, atualmente, são os fabricados à base de algodão, que são as malharias e os jeans sem etiqueta (calças e bermudas), vendidos a grandes magazines do exterior (BNB, 2006).

\section{COMPETITIVIDADE DA INDÚSTRIA TÊXTIL}

Segundo Prochnik e Fernandes (2000), a competitividade no fornecimento de matéria-prima é prejudicada pela obsolescência das máquinas e equipamentos, que utilizam tecnologia defasada, em que cerca de $60 \%$ da fiação e $56 \%$ da tecelagem e malharia têm idade superior a dez anos.

Prochnik (2002) salienta que a maior fragilidade do setor é encontrada no elo das empresas produtoras de fibras e filamentos artificiais e sintéticos, o que tem prejudicado a competitividade brasileira nos produtos derivados desses insumos (fios, tecidos, malhas e confecções), devido à oferta restrita a pequeno grupo de produtores, com pequena escala e dependente do suprimento da indústria petroquímica, além da elevada proteção contra importação, limitando o acesso à matéria-prima.

A produção de fibras químicas no Brasil tem se mantido estável nos últimos vinte anos, enquanto a produção mundial duplicou no mesmo período. Em 2002, o consumo de fibras naturais foi de $85,37 \%$ do total enquanto o consumo de fibras químicas chegou a $14,63 \%$.

Quanto ao fator tecnologia, a automação na indústria têxtil é feita através de microprocessadores e sistemas automáticos de transporte e movimentação, sendo que a utilização da microeletrônica, aplicada ao monitoramento, controle e automação da produção, tem procurado atender aos seguintes objetivos:

- Processo controlado por microprocessador;

- Coleta, armazenamento e registro de dados do processo;

- Controle do fluxo de material; 
- Controle de ajustes / regulagens das máquinas;

- Integração dos sistemas de monitoramento e regulagem das máquinas.

Uma tendência observada mundialmente é a utilização dos chamados sistemas integrados de gestão para facilitar o gerenciamento no ambiente globalizado e altamente competitivo. A modernização não se prende apenas ao processo produtivo, mas também em design, marketing e uma ampla variedade de aspectos organizacionais.

A competitividade da indústria perpassa por itens macroeconômicos, como a taxa de juros sobre o capital e a grande relevância do custo de energia elétrica sobre os custos de produção. Tomando por base relatório do Instituto de Estudos e Marketing industrial - IEMI (2003), encomendado pelo sindicato das indústrias têxteis do Ceará, sabe-se que a energia elétrica contribui para o custo de produção em cerca de $6,9 \%$ nas fiações, $8,1 \%$ nas tecelagens e $2,9 \%$ nas malharias.

A tendência é que a concorrência no mercado global, especificamente no que diz respeito à indústria têxtil, privilegiará aspectos relativos às especificações técnicas, financiamentos (prazos e custos financeiros), qualidade e rapidez na entrega. E ainda uma maior dependência dos produtos às variações da moda.

Podem-se citar ainda como fatores de competitividade: a incidência dos custos de produção, principalmente os indiretos como a energia elétrica; o clima de negócios referente à estabilidade política, segurança de funcionários, segurança de produção e dos embarques e dos sistemas legal e regulatório; e a infra-estrutura, abrangendo redes integradas de ferrovias e rodovias, portos e aeroportos de carga, custos de transporte, proximidade dos mercados, acesso às fontes de energia (inclusive alternativas) e telecomunicações.

\section{CONCLUSÕES}

Considerando-se todos os aspectos apresentados ao longo deste trabalho, algumas análises podem ser feitas a respeito dos desafios a serem suplantados pela indústria têxtil do Brasil, em geral, e do Nordeste, em particular, vislumbrando maior competitividade e inserção no mercado internacional, o que pode ser facilitado pelo aproveitamento dos seus aspectos positivos e eliminação dos aspectos negativos, estando estes e aqueles detalhados a seguir.

Alguns aspectos negativos inerentes à indústria têxtil brasileira e nordestina podem se constituir em barreiras para um melhor desempenho do setor, destacando-se os seguintes: 
- Alta dependência de incentivos fiscais para permanência das grandes empresas na Região Nordeste;

- Alto custo de transporte para aquisição de insumos e distribuição do produto final para as empresas nordestinas;

- Cenário atual do câmbio, com a valorização do real em relação ao dólar, dificultando a performance das empresas exportadoras e ocasionando diminuição de postos de trabalho e, em alguns casos, fechamento de empresas;

- Forte concorrência da China, dificultando a manutenção da competitividade dos produtos brasileiros, especialmente os de menor preço;

- Dificuldade das empresas brasileiras em fixar marca própria no mercado internacional, o que possibilitaria um melhor posicionamento competitivo;

- Tendência de aumento do consumo de produtos têxteis sintéticos;

- Tendência de maior preocupação em relação à legislação ambiental, principalmente junto às lavanderias (acabamento têxtil).

No intuito de que sejam aproveitados os aspectos positivos apresentados, bem como sejam eliminados os pontos negativos, há necessidade de suplantar alguns desafios inerentes à indústria têxtil brasileira e nordestina, destacando-se os seguintes:

- Buscar maior integração ao longo da cadeia produtiva.

- Tentar acordos preferenciais de acesso aos mercados dos Estados Unidos e União Européia, desde que em condições vantajosas, no caso desse último;

- Aumentar investimentos em desenvolvimento tecnológico, design e marca própria no mercado internacional;

- Prover um maior adensamento da cadeia produtiva nos estados nordestinos;

- Buscar alternativas para a minimização dos impactos do cenário macroeconômico na competitividade da indústria têxtil brasileira.

- Aumentar a competitividade dos produtos têxteis sintéticos.

Apesar de todas as dificuldades aparentes, espera-se, com esse trabalho, contribuir para a compreensão da realidade atual, dos desafios e oportunidades que se apresentam à indústria têxtil nordestina, para que tão importante setor produtivo possa se consolidar competitivamente no ambiente global de negócios. 


\section{REFERÊNCIAS}

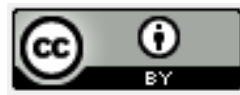

BNB. Política produtiva para o Nordeste - uma proposta. Fortaleza: BNB, 2006.

BRASIL, Ministério do Trabalho e Emprego. Relação Anual de Informações Sociais 2005.

CAMPOS, A.C.; PAULA, N. M. A indústria têxtil brasileira em um contexto de transformações mundiais. Rev. Econômica do Nordeste, Fortaleza, v. 37, no 4, p.592-608, out-dez. 2006.

CNI. Comércio exterior em perspectiva. Ano 14, n.3, dez 2004 / n.4, jan/2005.

COUTINHO, L.; FERRAZ, J. C. (coord.). Estudos da competitividade da indústria brasileira - ECIB. 2 ed. Campinas: Unicamp/Papirus, 1993.

DINIZ, C. C.; BASQUES, M. F. D. A industrialização nordestina recente e suas perspectivas. Fortaleza: BNB, 2004.

FARIA, R. Cadeia produtiva têxtil e vestuário: Programa TexBrasil. Palestra apresentada na Federação das Indústrias do Estado do Ceará, 03 mai. 2005.

FREIRE. L. L. R. Uma análise da indústria nordestina sob a ótica da competitividade empresarial. Dissertação (Mestrado em Economia). Fortaleza: CAEN/UFC, 2000.

GAZETA MERCANTIL. Panorama setorial: fiação, tecelagem e malharia. Vol I. São Paulo: Gazeta Mercantil, 1999.

IBGE. Valor da transformação industrial. Disponível em www.sidra.ibge.gov.br Acesso em 10 jul. 2008.

IEMI. Estudo da cadeia produtiva têxtil do estado do Ceará. Fortaleza: Sinditêxtil, 2003.

NUNES, F.R.M. et al. A gestão da cadeia de suprimento têxtil no Brasil analisada a partir das indústrias de confecções do estado do Ceará. In: NUNES, F.R.M.; ARRUDA, J.B.F. (orgs.) A logística a serviço da empresa e do desenvolvimento: a contribuição da pesquisa - melhores trabalhos do RIRL 2004. Fortaleza: Nutec, 2006.

PORTER, M. E. A vantagem competitiva das nações. Rio de Janeiro: Campus, 1993.

PROCHNIK, V; FERNANDES, T. Oportunidades na cadeia têxtil do Nordeste. In: HAGUENAUER, L; PROCHNIK, V. Identificação de cadeias produtivas e oportunidades de investimento no Nordeste do Brasil. Fortaleza: BNB, 2000.

PROCHNIK, V. Cadeia: têxtil e confecções. Estudo da competitividade de cadeias integradas no Brasil: impactos das zonas de livre comércio. Nota Técnica Final. UNICAMP: Campinas, 2002. 
ROCHA, R. E. V. Documento síntese de acompanhamento do setor têxtil. Subsídios para Avaliação, Formulação e Atualização das Políticas e Programas de Financiamento Setorial/Atividade no BNB. Fortaleza: BNB, 2007. (Versão preliminar - circulação interna).

VERGARA, S. C. Projetos e relatórios de pesquisa em administração. 5 ed. São Paulo: Atlas, 2004.

VIANA, F. L. E. Os desafios da indústria têxtil e de confecções. Revista BNB Conjuntura Econômica. Fortaleza, n.4, mai-jun, 2005a.

A indústria têxtil e de confecções no Nordeste: características, desafios e oportunidades. Série Documentos do ETENE nº 06. Fortaleza: BNB, 2005 b.

VIDAL, M. F.; CARNEIRO, W. M. A. Cotonicultura nos cerrados nordestinos: produção, mercados e estruturação da cadeia produtiva. Série Documentos do ETENE $\mathrm{n}^{\circ} 13$. Fortaleza: BNB, 2006. 